\title{
PERICULOSIDADE DOS PRODUTOS E RESÍDUOS QUÍMICOS DA ATENÇÃO HOSPITALAR*
}

Taiza Florêncio Costa ${ }^{1}$, Vanda Elisa Andres Felli²

\begin{abstract}
RESUMO: O presente estudo descritivo teve por objetivo identificar a periculosidade atribuível aos produtos e resíduos químicos da atenção hospitalar. A instituição campo de estudo foi o Hospital Universitário da Universidade de São Paulo; as informações foram coletados em documentos dos almoxarifados e farmácia da instituição. A análise dos dados evidenciou 23 compostos químicos com potencial inflamável, corrosivo, reativo e tóxico, tanto para produtos quanto para resíduos, sendo esses os ácidos acético, peracético, tricloroacético, além de acetona, álcool etílico, benzina, benzocaina, ciclofosfamida, éter, formol, ganciclovir, halotano, hidróxido de potássio, hipoclorito de sódio, isoflurano, glutaraldeído, óleo mineral, óxido nítrico, permanganato de potássio, peróxido de hidrogênio, sevoflurano, tintura de benjoim e xilol. As características de periculosidade dos produtos e seus respectivos resíduos devem ser identificadas, analisadas e contempladas no Plano de Gerenciamento de Resíduos Químicos Perigosos, evitando riscos para saúde do trabalhador, saúde pública e meio ambiente. PALAVRAS-CHAVE:Compostos químicos; Resíduos químicos; Hospitais de ensino; Saúde ocupacional; Saúde ambiental.
\end{abstract}

\section{DANGEROUSNESS OF CHEMICAL PRODUCTS AND WASTE FROM HOSPITAL CARE}

ABSTRACT: This descriptive study aimed to identify the dangerousness attributable to chemical products and waste resulting from hospital care. The institution serving as field of study was the University Hospital of the University of São Paulo; information was collected from documents from the institution's storerooms and pharmacy. Analysis of the data found evidence for 23 chemical compounds with flammable, corrosive, reactive or toxic potential, both for products or waste; these were acetic acid, peracetic acid and trichloroacetic acid, as well as acetone, ethyl alcohol, benzene, benzocaine, cyclophosphamide, ether, formalin, ganciclovir, halothane, potassium hydroxide, sodium hypochlorite, isoflurane, glutaraldehyde, mineral oil, nitric oxide, potassium permanganate, hydrogen peroxide, sevoflurane, tincture of benzoin and xylol. The dangerousness characteristics of the products and their respective wastes, must be identified, analyzed and considered in the Management Plan for Dangerous Chemical Wastes, so avoiding risks to workers' health, public health and the environment.

KEYWORDS: Chemical compounds; Chemical waste; Teaching hospitals; Occupational health; Environmental health.

\section{PELIGROSIDAD DE LOS PRODUCTOS Y RESIDUOS QUÍMICOS DE LA ATENCIÓN HOSPITALAR}

RESUMEN: Este estudio descriptivo tuvo por objetivo identificar la peligrosidad de los productos y residuos químicos de la atención hospitalar. La institución campo de estudio fue el Hospital Universitario de la Universidad de São Paulo; las informaciones fueron recogidas en documentos de los depósitos y farmacia de la institución. El análisis de los datos mostró 23 compuestos químicos con potencial inflamable, corrosivo, reactivo y tóxico, tanto para productos como para residuos, siendo eses los ácidos acético, peracético, tricloroacético, además de acetona, álcohol etílico, benzina, benzocaína, ciclofosfamida, éter, formol, ganciclovir, halotano, hidróxido de potásio, hipoclorito de sodio, isoflurano, glutaraldeído, óleo mineral, óxido nítrico, permanganato de potasio, peróxido de hidrogenio, sevoflurano, tintura de benjoim y xilol. Las características de peligrosidad de los productos y sus respectivos residuos deben ser identificadas, analizadas y contempladas en el Plan de Gerenciamento de Residuos Químicos Peligrosos, evitando riesgos para la salud del trabajador, salud pública y medio ambiente. PALABRAS CLAVE: Compuestos químicos; Residuos químicos; Hospitales de enseñanza; Salud ocupacional; Salud ambiental.

\footnotetext{
* Extraído da tese de doutorado intitulada Gerenciamento de resíduos químicos perigosos manuseados pela enfermagem de um Hospital Universitário, apresentada à Escola de Enfermagem da Universidade de São Paulo em 2009.

${ }^{1}$ Enfermeira. Pós-Doutoranda pelo Programa Nacional de Pós-Doutorado PNPD /CAPS da Escola e Enfermagem da Universidade de São Paulo - EE USP.

${ }^{2}$ Enfermeira. Doutora em Enfermagem. Professora do Departamento de Orientação Profissional e do Programa de Pós-Graduação da EE USP.
}

Autor correspondente:

Taiza Florêncio Costa

Universidade de São Paulo

Av. Dr. Enéas de Carvalho Aguiar, 419-05403-000 -São Paulo-SP-Brasil

Email: taizaflorencio@usp.br
Recebido: $07 / 02 / 2012$ Aprovado: 30/05/2012 


\section{INTRODUÇÃO}

O uso de substâncias químicas, com princípios ativos com características de periculosidade é, muitas vezes, imprescindível na assistência ao paciente no ambiente hospitalar, na forma de substância química de uso medicamentoso, ou não. Seu uso pode comprometer a saúde dos trabalhadores que as manipulam, a saúde da população e agredir outras formas de vida no meio ambiente. Contudo, as substâncias químicas constituem instrumentos de trabalho necessários para a assistência à saúde ${ }^{(1)}$.

Os trabalhadores expõem-se às cargas químicas na execução do seu processo de trabalho na medida em que as cargas de trabalho constituem elementos que interatuam entre si e com o corpo do trabalhador, gerando processos de desgastes ${ }^{(2)}$. Em estudo sobre a saúde dos trabalhadores de enfermagem verificou-se que foram detectadas 145 substâncias químicas as quais os trabalhadores referiram estarem expostos durante o exercício de suas atividades ${ }^{(3)}$. Entre as centenas de substâncias químicas manuseadas pelos trabalhadores de enfermagem encontram-se as com potencial para geração de resíduos químicos perigosos (RQP).

De acordo com dados da Pesquisa Nacional de Saneamento Básico, realizada pelo Instituto Brasileiro de Geografia e Estatísticas, são coletadas diariamente 228.413 toneladas de resíduos no Brasil. Em geral, estima-se que $1 \%$ a $2 \%$ desses corresponda aos resíduos de serviço de saúde - $\operatorname{RSS}^{(4)}$.

O desconhecimento em relação às estratégias preventivas quanto à exposição a substâncias químicas com princípio ativo, que lhes confere periculosidade, se estende ao desconhecimento em relação ao gerenciamento de seus resíduos químicos perigosos gerados na prestação da assistência ao paciente. As drogas antineoplásicas, esterilizantes, gases anestésicos, entre outros produtos químicos perigosos, são causadores desde problemas dermatológicos até neoplasias ${ }^{(5)}$. Essas propriedades também são atribuíveis aos seus respectivos resíduos.

Para caracterizar os produtos geradores de resíduos químicos perigosos as instituições hospitalares devem lançar mão dos critérios estabelecidos pela Resolução ANVISA n. 306, de 07 de dezembro de 2004 que dispõe sobre o Regulamento Técnico para o gerenciamento de $\mathrm{RSS}^{(6)}$ e também do dispositivo da Companhia de Tecnologia de Saneamento Ambiental (CETESB), por meio da Norma Técnica P4.262/2007 que trata do Gerenciamento de Resíduos Químicos Pro- venientes de Estabelecimentos de Serviços de Saúde ${ }^{(7)}$ assim como do dispositivo legal do Estado de São Paulo representado pela Portaria CVS - 21, de 10/09/2008, do Centro de Vigilância Sanitária que trata da Norma Técnica sobre Gerenciamento de Resíduos Perigosos de Medicamentos em Serviços de Saúde ${ }^{(8)}$.

Embasando os dispositivos legais a Norma Brasileira Regulamentadora n. 10004 estabelece que se pode considerar um resíduo químico hospitalar perigoso quando esse apresenta, pelo menos, uma das seguintes propriedades: inflamabilidade, corrosividade, reatividade, toxicidade ${ }^{(9)}$. Esta Norma fundamenta a Resolução CONAMA 358/2005 que dispõe sobre o tratamento e a disposição final dos $\operatorname{RSS}^{(10)}$.

A Resolução CONAMA ${ }^{(10)}$, classifica os resíduos dos serviços de saúde em Grupos A,B,C,D,E. Pertencem ao Grupo B os resíduos contendo substâncias químicas que podem apresentar risco à saúde pública ou ao meio ambiente, dependendo de suas características de periculosidade. Compreendem também os produtos hormonais, antimicrobianos, citostáticos, antineoplásicos, imunossupressores, digitálicos, imunomoduladores, anti-retrovirais, medicamentos controlados pela Portaria MS 344/98. Ainda, pertencem ao Grupo B os resíduos de saneantes, desinfetantes, desinfestantes; resíduos contendo metais pesados; reagentes para laboratório, inclusive os recipientes contaminados por estes; efluentes de processadores de imagem (reveladores e fixadores); efluentes dos equipamentos automatizados utilizados em análises clínicas; e demais produtos considerados perigosos, conforme classificação da NBR $10.004^{(9)}$ da ABNT (tóxicos, corrosivos, inflamáveis e reativos).

$\mathrm{Na}$ caracterização dos produtos químicos geradores de resíduos químicos perigosos destacam-se, ainda, as Normas da ABNT intituladas "Produtos Químicos" - Informações sobre Segurança, Saúde e Meio Ambiente, de setembro de 2009, e ligadas ao Sistema Globalmente Harmonizado (GHS) de informação de segurança de produtos químicos perigosos. As citadas Normas tratam de informações sobre segurança, saúde e meio ambiente; são compostas por quatro partes: NBR 14.725-1: Terminologia; NBR 14.725-2: Sistema de Classificação de Perigo; NBR 14.725-3: Rotulagem; NBR 14.725-4: Ficha de Informações de Segurança (FISPQ). As referidas Normas substituem a edição da ABNT NBR 14.725/05, a qual foi tecnicamente revisada e desmembrada em partes. Tão recente documento representa o mais importante 
dispositivo legal com vistas à classificação dos Resíduos Químicos Perigosos ${ }^{(11)}$.

Os resíduos químicos pertencentes ao Grupo B, com características de periculosidade, quando não forem submetidos a processo de reutilização, recuperação ou reciclagem, devem ser submetidos a tratamento e disposição final específicos. Os resíduos químicos sem características de periculosidade não necessitam de tratamento prévio. Quando no estado sólido podem ter disposição final em aterro licenciado e quando no estado líquido podem ser lançados em corpo receptor ou na rede pública de esgoto, desde que atendam respectivamente as diretrizes estabelecidas pelos órgãos ambientais, gestores de recursos hídricos e de saneamento competentes ${ }^{(7-8)}$.

Cabe ao estabelecimento gerador de RQP gerenciar seus resíduos por meio de um Plano de Gerenciamento de Resíduos Químicos Perigosos ${ }^{(6)}$. Para tanto, o primeiro passo é que a instituição identifique as características de periculosidade de produtos e resíduos químicos.

Frente às lacunas de estudos quanto a identificação da periculosidade dos produtos e resíduos químicos e da responsabilidade da instituição na elaboração do Plano de Gerenciamento de Resíduos Químicos Perigosos $^{(6-7)}$, buscou-se no presente trabalho identificar a periculosidade dos produtos e resíduos químicos da atenção hospitalar, como uma forma de subsídio ao Plano de Gerenciamento de Resíduos Químicos Perigosos (PGRQP) da instituição campo de estudo.

\section{MÉTODO}

Trata-se de um estudo do tipo descritivo, uma vez que pretende demonstrar a periculosidade dos produtos e resíduos decorrentes da assistência no ambiente hospitalar. A instituição campo de estudo foi o Hospital Universitário da Universidade de São Paulo (HU-USP). Os dados foram coletados no período de abril a junho de 2008, utilizando-se o instrumento denominado Formulário para identificação nos estoques dos produtos químicos de uso médico-hospitalar do almoxarifado e farmácia do HU-USP.

Após aprovação do projeto pelo Comitê de Ética e Pesquisa do Hospital, protocolo de número 785/07, e contato com a direção do serviço de farmácia e almoxarifado, os dados foram coletados, classificados e analisados segundo as características de periculosidade registradas nas Fichas de Informações de Segurança de Produtos Químicos - FISPQ ${ }^{(11)}$.

\section{RESULTADOS}

Os compostos químicos identificados com periculosidade atribuível aos produtos e resíduos químicos da atenção hospitalar são apresentados no quadro 1.

Quadro 1 - Produtos da atenção hospitalar geradores de resíduos químicos perigosos segundo a classificação de periculosidade. São Paulo, 2008

\begin{tabular}{|c|c|c|}
\hline $\mathbf{N}$ & Produto & Periculosidade \\
\hline 1 & Acetona & tóxico /inflamável/ reativo \\
\hline 2 & Acido Acético & tóxico/ inflamável/reativo \\
\hline 3 & Ácido Peracético & tóxico/reativo \\
\hline 4 & Ácido tricloroacético & tóxico/corrosivo \\
\hline 5 & Álcool Etílico & tóxico /inflamável \\
\hline 6 & Benzina & tóxico /inflamável \\
\hline 7 & Benzocaina & tóxico/inflamável \\
\hline 8 & Ciclofosfamida & tóxico \\
\hline 9 & Éter & tóxico /inflamável \\
\hline 10 & Formaldeído & tóxico/inflamável/corrosivo/reativo \\
\hline 11 & Ganciclovir & tóxico \\
\hline 12 & Halotano & tóxico \\
\hline 13 & Hidróxido de Potássio & tóxico/corrosivo/reativo \\
\hline 14 & Hipoclorito de Sódio & tóxico/corrosivo/reativo \\
\hline 15 & Isoflurano & tóxico \\
\hline 16 & Glutaraldeido & tóxico/ reativo/corrosivo \\
\hline 17 & Òleo Mineral & tóxico \\
\hline 18 & Óxido Nítrico & tóxico/reativo \\
\hline 19 & Permanganato Potássio & tóxico/oxidante \\
\hline 20 & Peróxido de Hidrogênio & tóxico/reativo \\
\hline 21 & Sevoflorano & tóxico \\
\hline 22 & Tintura de Benjoim & tóxico/inflamável \\
\hline 23 & Xilol & tóxico/inflamável \\
\hline
\end{tabular}

\section{DISCUSSÃO}

Os dados do quadro 1 evidenciam 23 compostos considerados perigosos tanto como produtos como resíduos químicos da atenção hospitalar; destaca-se o fato de apresentarem em comum a toxicidade. $\mathrm{O}$ conhecimento do potencial inflamável, corrosivo, reativo ou tóxico dos produtos e resíduos é de extrema importância, pois possibilita a promoção de medidas de segurança. Para tanto, cabe analisar as características de periculosidade dos produtos identificados, propriedades essas atribuíveis aos resíduos gerados e a serem tratados por meio da implantação do PGRQP.

A acetona é um líquido aquoso, sem coloração, incompatível com material oxidante e ácidos, classificada como inflamável e tóxica, e oferece potencial de toxicidade à vida humana e aquática. Seu vapor é irritante para os olhos, nariz e garganta, se inalado pode causar dificuldade respiratória ou perda da consciência. A rotulagem dos resíduos do produto deve conter o símbolo de risco inflamável que indica a propriedade 
da acetona em queimar-se instantaneamente ${ }^{(6-7,11)}$. Os resíduos de acetona no setor hospitalar são gerados pelo seu uso como solvente dos esmaltes existentes nas unhas de pacientes.

O ácido acético é um líquido aquoso, sem coloração e de odor forte que, além de produzir vapores, é incompatível com oxidantes fortes, ácido nítrico, peróxido de sódio e bases fortes. esse ácido possui grau de risco tóxico e inflamável, oferece, também, potencial de toxicidade aquática. Seu vapor é irritante para o nariz e garganta, se inalado pode causar tosse, náusea, vômito ou dificuldade respiratória. A rotulagem dos resíduos deve conter o símbolo de corrosivo que irá identificar a capacidade do ácido acético em destruir tecidos vivos e/ou materiais inertes ${ }^{(6-7,11)}$. O ácido acético já diluído é usado em aplicação tópica no colo uterino com a finalidade de estabelecer diagnóstico clínico.

$\mathrm{O}$ ácido peracético é um líquido sem coloração, de odor forte e produz vapores. O produto é corrosivo para a maioria dos metais, sendo classificado com características de reatividade e toxicidade, seu vapor é irritante para os olhos, nariz e garganta. A rotulagem dos resíduos deve conter o símbolo de oxidante por ser o ácido peracético, um agente que desprende oxigênio e favorece a combustão, podendo inflamar substâncias combustíveis ou acelerar a propagação de incêndio. É, portanto, necessário evitar qualquer contato do ácido peracético com substâncias combustíveis pelo perigo de incêndio ${ }^{(6-7,11)}$. A geração do resíduo ocorre pelo uso do produto como esterilizante e desinfetante.

O ácido tricloroacético é solúvel em água, pode gerar vapores tóxicos que podem causar cefaleia, náuseas e tontura; o contato com a pele ou olhos leva à irritação ou queimaduras. Classifica-se como tóxico e corrosivo, sendo muito tóxico aos organismos aquáticos. A rotulagem dos resíduos deve conter o símbolo de corrosivo ${ }^{(6-7,11)}$. Entre os usos do ácido tricloroacético, destaca-se o uso tópico em órgãos genitais para tratar infecções virais da pele, resultando também na formação de resíduos após o procedimento.

$\mathrm{O}$ álcool é líquido aquoso, sem coloração, produz vapor e é classificado como tóxico para a saúde humana e aquática; apresenta elevado potencial de inflamabilidade. Seu vapor é irritante para os olhos, nariz e garganta. A rotulagem dos resíduos deve conter o símbolo de risco inflamável que indica a sua propriedade em queimar-se instantaneamente ${ }^{(6-7,11)}$. O produto gera resíduos pelo uso como antisséptico na concentração $70 \%$.

A benzina é um líquido incolor e de odor característico suave. sendo incompatível com oxidantes fortes, ácido nítrico, clorados (como cloro líquido) e oxigênio concentrado (como peróxidos). É classificada como inflamável, produz vapor irritante extremamente prejudicial à saúde, além da toxicidade aquática e do solo, podendo contaminar o lençol freático. Seu vapor é irritante para os olhos, nariz, garganta; se ingerido, pode causar irritação gástrica e intestinal; se aspirado, pode resultar em acúmulo de fluídos nos pulmões; se absorvida pela pele, poderá ser irritante. Apresenta ainda, efeito narcótico. A rotulagem dos resíduos deve conter o símbolo de risco inflamável que indica a propriedade da benzina em queimar-se instantaneamente ${ }^{(6-7,71)}$. A geração de resíduo de benzina na atenção hospitalar ocorre pelo seu uso como solvente.

A benzocaína é inodora, de cor branca, sendo solúvel em éter etílico e pouco solúvel em água fria. A substância sob combustão pode produzir monóxido de carbono, quando misturada com nitratos pode explodir. É classificada como de risco para saúde e inflamável. A inalação leva à irritação do trato respiratório até a diminuição da frequência respiratória; a ingestão leva à excitação do sistema nervoso; o contato com a pele pode ocasionar vermelhidão e dermatite de contato, além de irritação e dor ao contato ocular. A rotulagem dos resíduos deve conter o símbolo de risco tóxico que indica a propriedade da benzocaína em introduzir-se no organismo por inalação, absorção ou ingestão, ocasionando efeitos graves ${ }^{(6-8,11)}$. Entre os usos da benzocaína encontra-se o de anestésico local de uso prévio em pequenas cirurgias e exames resultando em resíduos ao término do procedimento.

A ciclofosfamida constitui-se como parte de um grupo de fármacos antineoplásicos capaz de inibir o crescimento das células tumorais com uma toxicidade tolerável sobre as células normais. É classificada como uma substância tóxica, pois promove a carcinogenicidade para humanos. A inalação leva à irritação do trato respiratório até a diminuição da frequência respiratória; a ingestão leva à excitação do sistema nervoso; o contato com a pele pode ocasionar vermelhidão e dermatite de contato, além de irritação e dor ao contato ocular. A ciclofosfamida dispersa-se no ambiente de trabalho, no estado sólido, na forma de pó ou, com maior frequência, no estado líquido, na forma aerodispersa. A via percurtânea é a principal via de absorção; se a exposição é acompanhada de uma ação lesiva na pele, a absorção é facilitada. A rotulagem dos resíduos deve conter o símbolo de risco tóxico que indica a propriedade da ciclofosfamida em introduzir-se no organismo por inalação e absorção através da pele, levando a danos à 
saúde, na maior parte das vezes, muito graves ${ }^{(6,8,11)}$. A geração do resíduo do produto ocorre pelo seu uso como quimioterápico antineoplásico.

$\mathrm{O}$ éter é um produto líquido aquoso, sem coloração e produz vapor. A substância é volátil, sendo classificada como inflamável e tóxica à saúde, além de oferecer potencial de toxicidade aquática. Os resíduos são gerados pelo uso no tratamento de miíase. Seu vapor é irritante para os olhos, nariz e garganta e, se inalado, causará náusea, vômito, cefaleia e até perda da consciência. Na forma líquida é irritante para a pele. A rotulagem dos resíduos deve conter o símbolo de risco de inflamável, que indica a propriedade do éter em queimar-se instantaneamente $e^{(6-7,11)}$.

O formaldeído é um líquido aquoso, sem coloração e odor irritante. O produto é incompatível com oxidantes fortes, álcalis, ácidos, fenóis e uréia, sendo classificado como inflamável, reativo, corrosivo e tóxico à saúde humana e vida aquática. A geração de resíduos do produto é decorrente do uso como conservante de tecidos humanos, desinfetante e esterilizante. O produto pode ser absorvido pelas vias oral, cutânea e inalatória, apresenta elevado potencial de irritabilidade e carcinogenicidade. A rotulagem dos resíduos deve conter o símbolo de risco de corrosividade que indica a propriedade do formaldeído causar destruição de tecidos vivos e/ou materiais inertes ${ }^{(6-7,11)}$.

O ganciclovir constitui-se em um fármaco antiviral, de potencial antineoplásico, sendo classificado como um substância tóxica pelas características de carcinogenicidade, teratogenicidade e genotoxicidade para humanos. Assim como a ciclofosfamida, ao ser inalado, ocasiona a irritação do trato respiratório até a diminuição da freqüência respiratória; a ingestão leva à excitação do sistema nervoso, o contato com a pele pode ocasionar vermelhidão e dermatite de contato, além de irritação e dor ao contato ocular. É um produto de combustão, dispersa-se no ambiente de trabalho no estado sólido, na forma de pó ou, com maior frequência, no estado líquido, na forma aerodispersa. A via percurtânea é a principal via de absorção; se a exposição for acompanhada de uma ação lesiva na pele, a absorção será facilitada. A rotulagem dos resíduos deve conter o símbolo de risco tóxico que indica a propriedade do ganciclovir introduzir-se no organismo, por inalação e absorção levando a graves problemas de saúde ${ }^{(6,8,11)}$. A geração do resíduo do produto ocorre pelo seu uso como quimioterápico antineoplásico.

O glutaraldeído é um líquido amarelo claro e que se mistura com água. O produto reage com álcalis, aminas e ácidos fortes. Sua decomposição gera gases nitrosos, monóxido de carbono e ácido clorídrico gasoso; é classificado como reativo, corrosivo e toxico à saúde humana e aquática. Os resíduos de glutaraldeído são derivados do uso como esterilizante de artigos e instrumentos sensíveis ao calor e desinfecção de artigos semi-críticos. A substância, quando absorvida pelas vias oral, dérmica e/ou inalatória, apresenta elevado potencial de irritabilidade. A rotulagem dos resíduos deve conter o símbolo de risco de corrosividade que indica a propriedade do glutaraldeído em causar destruição de tecidos vivos ${ }^{(6-7,11)}$.

O halotano é um líquido incolor, pouco solúvel. A substância é incompatível com borracha, plástico e oxidantes fortes. É classificado como um substância tóxica, irritante e com potencial para carcinogenicidade. Os resíduos são gerados pelo uso do fármaco em anestesia inalatória nas cirurgias e exames. Seu vapor é irritante para as mucosas, sistemas nervoso e reprodutor, além de efeitos hepatotóxicos. A rotulagem dos resíduos deve conter o símbolo de risco tóxico que indica a propriedade do halotano em introduzir-se no organismo por inalação e absorção, através da pele, possibilitando danos à saúde ${ }^{(6,8,11)}$.

O hidróxido de potássio é um líquido aquoso e incolor, reage com água liberando calor e vapor, é classificado como de risco à saúde, além de reativo, corrosivo e tóxico à vida aquática. O resíduo do produto é gerado pelo uso em Ginecologia e Obstetrícia como agente de diagnóstico. Os danos causados pelo produto envolvem irritação ocular, nasal, pulmonar, queimaduras na pele e, no caso de ingestão, pode levar à morte ${ }^{(6-8,11)}$.

O hipoclorito de sódio é um líquido aquoso, de coloração verde para amarelo, e de odor característico. O produto libera gases tóxicos em contato com ácidos. É corrosivo, apresenta reatividade, sendo também tóxico para saúde humana, além de afetar rios e cursos d’água por alteração do $\mathrm{pH}$ do cloro ativo. $\mathrm{O}$ resíduo de hipoclorito é gerado pelo uso do produto como desinfetante. Seu vapor pode levar à irritação dos olhos, nariz e garganta e pele. A rotulagem dos resíduos deve conter o símbolo de risco corrosivo que indica sua propriedade em causar destruição dos tecidos vivos e/ ou materiais inertes ${ }^{(6-7,11)}$.

O isoflurano é um fármaco indicado para indução e manutenção de anestesia geral; os resíduos são gerados pelo uso do fármaco em anestesia inalatória. Seu vapor atua de maneira irritante para as mucosas, sistema nervoso e reprodutor, além de efeitos hepatotóxicos. 
A rotulagem dos resíduos deve conter o símbolo de risco tóxico que indica a propriedade do isoflurano em introduzir-se no organismo por inalação, possibilitando danos à saúde $\mathrm{e}^{(6,8,11)}$.

O óleo mineral é um líquido límpido e de odor característico, o produto é incompatível com água e aquecimento. É classificado como grau de risco à saúde em razão da liberação de vapores tóxicos quando em combustão. No estado líquido oferece perigo de contaminação de rios e lagos, e, caso venha a contaminar o solo, poderá afetar a qualidade das águas e dos lençóis freáticos. A geração de resíduos do produto é em função do seu uso como lubrificante. Seu vapor é irritante para os olhos, nariz, garganta e pulmões. A rotulagem dos resíduos deve conter o símbolo de risco ao meio ambiente, que indica a propriedade do óleo mineral de contaminar os recursos naturais ${ }^{(6-7,11)}$.

O óxido nítrico é um gás comprimido, sem coloração, odor sufocante desagradável e produz vapor. $\mathrm{O}$ gás reage com a água, produzindo ácido nítrico $\mathrm{e}$ reage com o ar, formando o tetróxido de nitrogênio e gerando uma nuvem de vapor venenoso de cor marron amarelado. É um gás incompatível com os materiais combustíveis, metais e amônia, é classificado, como tóxico à saúde, reativo, além de possuir propriedade de oxidante. O uso medicinal do óxido nítrico está relacionado ao tratamento da hipertensão pulmonar persistente do recém-nascido. Seu vapor é irritante para os olhos, nariz e garganta, quando inalado pode causar dificuldade respiratória ou perda da consciência. A rotulagem dos resíduos deve conter o símbolo de risco tóxico que indica a propriedade do gás em introduzirse no organismo por inalação, causando danos à saúde humana ${ }^{(6,8,11)}$. Os resíduos do produto são gerados por sua eliminação no ambiente.

O permanganato de potássio tem aparência semelhante a um cristal sólido, roxo escuro, sem odor. A substância reage com alguns ácidos, a exemplo do ácido sulfúrico, o que pode levar à explosão. É classificado como grau de risco à saúde, além de ser um potente oxidante. Deve ser identificado com rótulo de risco de produto oxidante. $\mathrm{O}$ resíduo do permanganato de potássio é gerado pelo seu uso como antisséptico e germicida das afecções da pele. É um produto irritante para a pele e olhos, se ingerido, causa danos ao sistema digestivo e sistema nervoso. A rotulagem dos resíduos com o símbolo de risco oxidante indica a propriedade do permanganato desprender oxigênio e favorecer a combustão, podendo, assim, inflamar substâncias combustíveis ou acelerar a propagação de incêndios ${ }^{(6-7,11)}$.
O peróxido de hidrogênio é um líquido aquoso, sem coloração e produz vapor. A substância é incompatível com materiais oxidáveis, como prata, ferro, entre outros. O produto é, tóxico, reativo e oxidante, além de oferecer risco a saúde humana é prejudicial aos organismos aquáticos. A geração de resíduos do produto ocorre pelo seu uso como antisséptico. Seu vapor é irritante para os olhos, nariz, garganta e mucosas, em geral; se inalado pode causar dificuldade respiratória ou perda da consciência. A rotulagem dos resíduos deve conter o símbolo de risco oxidante que indica a propriedade do peróxido de hidrogênio em desprender oxigênio e favorecer a combustão pode, assim, inflamar substâncias combustíveis ou acelerar a propagação de incêndios ${ }^{(6-7,11)}$.

O sevoflurano, a exemplo do halotano e do isoflurano, tem ação anestésica e os resíduos do produto são decorrentes dos vapores eliminados nas salas cirúrgicas. O sevoflurano ainda é estudado quanto à carcinogenicidade e efeitos sobre o feto, não sendo, assim, indicada a exposição de gestantes (pacientes e/ou trabalhadoras) ao anestésico, uma vez que os estudos ainda são inconclusivos quanto à periculosidade nesse grupo. A exposição clínica e/ou ocupacional ao anestésico acarreta, no entanto, eventos adversos no sistema respiratório, cardiovascular, digestivo e urogenital $l^{(6,8,11)}$.

A tintura de benjoim é um líquido pardo, de odor característico e miscível com água. A substância é incompatível com oxidantes fortes, é classificada como tóxica e inflamável. Os resíduos são gerados pelo uso como solvente. Trata-se de um produto irritante para as mucosas e sistema nervoso. Os vapores podem formar misturas explosivas com o ar. A rotulagem dos resíduos deve conter o símbolo de risco inflamável que indica a propriedade da substância em queimar-se instantaneamente $e^{(6-7,11)}$.

O xilol é um líquido aquoso, sem coloração, odor doce, flutua na água e produz vapor. A substância é incompatível com oxidantes fortes, é classificada como inflamável e tóxica para saúde humana e ambiente aquático. Os resíduos de xilol são derivados do seu uso como solvente. O produto é tóxico, se ingerido; seu vapor é irritante para os olhos, garganta, sistema respiratório e sistema nervoso. A rotulagem dos resíduos deve conter o símbolo de risco inflamável que indica a propriedade do xilol em queimar-se instantaneamente $\mathrm{e}^{(6-7,11)}$.

Os riscos atribuídos aos produtos químicos perigosos, mostrados no quadro 1, estão diretamente relacionados a seus resíduos que são manuseados por 
trabalhadores intra e extra estabelecimento, sendo, amplamente, manuseados pela enfermagem, seja na assistência ou em sua decorrência.

Estudos revelam o envio de produtos químicos para os setores assistenciais e, consequentemente, o manuseio de produtos geradores de resíduos químicos perigosos pela enfermagem durante a assistência ao paciente ou em função da sua efetivação $0^{(13-17)}$.

Pesquisas entre enfermeiros detectaram 100\% de referencias de exposição à benzina, sendo esta ainda citada como principal substância causadora de problemas de saúde, assim como os antineoplásicos e o glutaraldeído ${ }^{(13-14)}$.

O formaldeido pode ocasionar uma série de problemas à saúde humana, a exemplo de irritação ocular, respiratória e dermatites. Quanto à toxicidade ambiental, há recomendações para não lançar seus resíduos nos esgotos, guardá-los em recipientes fechados e eliminálos de acordo com a regulamentação em vigor ${ }^{(15-16)}$.

A percepção da enfermagem quanto aos efeitos das substâncias químicas dá-se, geralmente, a longo prazo $^{(17)}$. O reconhecimento tardio dos efeitos das substâncias também pode ser atribuído aos resíduos perigosos gerados no seu uso durante a assistência os resíduos gerados por substâncias químicas, além de perigosos para saúde do trabalhador, podem causar problemas à saúde pública e ao meio ambiente. As cargas decorrentes de produtos químicos podem ser apontadas como a principal exposição dos trabalhadores de Unidade de Centro de Material ${ }^{(18)}$.

As características dos produtos químicos perigosos manuseados pela enfermagem estão diretamente relacionadas aos seus resíduos os quais, quando inadequadamente gerenciados, propagam seu potencial de inflamabilidade, corrosividade, reatividade e toxicidade aos trabalhadores em geral, à comunidade à fauna $\mathrm{e}$ flora. Esse fato, ainda que de forma gradativa, é foco de estudos e preocupação das autoridades ambientais e administradores quanto à sua classificação para o gerenciamento dos RQP e, mais especificamente, os gerados no ambiente hospitalar que representa um grande gerador na categoria RSS.

Os referidos produtos podem subsidiar a proposta de um modelo de um PGRQP na atenção hospitalar. Tal plano deverá ser incorporado como parte integrante do Plano de Gerenciamento de Resíduos de Serviços de Saúde (PGRSS) da instituição.

As características de periculosidade desses produtos e resíduos da atenção hospitalar indicam a necessidade dos mesmos serem contemplados em detalhes no PGRQP da instituição campo de estudo. Tal plano envolve desde a segregação até o tratamento e disposição final de resíduos de produtos químicos utilizados ou vencidos. Após adotada uma classificação para os RSS, o próximo passo para elaborar o PGRSS refere-se à segregação, que significa separação entre os diferentes grupos e que deve ser efetuada na fonte geradora no momento de sua geração e pelo próprio funcionário que realizou o procedimento ${ }^{(14)}$.

Embora os dispositivos legais estabeleçam como RQP os derivados de produtos com potencial carcinogênico, mutagênico, teratogênico, assim como os com propriedades inflamáveis, corrosivas e reativas ${ }^{(19)}$, a legislação brasileira, além de conflitante, é insuficiente em sua aplicação.

Os RSS têm sido gerados em todas as áreas hospitalares sendo submetidos a critérios específicos de classificação e tratamento, tanto no Brasil quanto no exterior $^{(20)}$. Baseado nas características e no volume dos RSS gerados, o PGRSS deve ser elaborado estabelecendo as diretrizes de seu manejo ${ }^{(21)}$.

A classificação dos resíduos é uma atividade complexa, representa um desafio inclusive nos países desenvolvidos, e, deste modo, devem-se estabelecer critérios rigorosos para caracterizar o perigo dos resíduos de saúde ${ }^{(22)}$. A interação do trabalhador de enfermagem com instrumentos de trabalho indica a exposição e os riscos de doenças no trabalho ${ }^{(23)}$.

Relativo aos resíduos do grupo B percebe-se a adoção de condutas diferenciadas e que também não atendem a legislação vigente, percebe-se que esta deficiência tem seu início desde a identificação ${ }^{(21)}$.

É interessante ver que ainda há muito o que fazer e estudar sobre o assunto que envolve a identificação, análise e gerenciamento dos RSS, nos seus mais diversos grupos e, mais especificamente, quando trata-se do gerenciamento dos resíduos de produtos químicos perigosos por meio do $\mathrm{PGRQP}^{(24)}$.

\section{CONCLUSÃO}

O presente estudo nos permite fazer algumas considerações quanto aos produtos de uso médico-hospitalar, contendo substâncias com potencial para geração de RQP manuseados por trabalhadores intra e extra estabelecimento; destacando-se, entre esses profissionais, os de enfermagem.

Concluiu-se que os produtos químicos identificados representam prioridade do PGRQP da instituição campo de estudo uma vez que os 23 produtos são, em 
algum momento, enviados para algum setor assistencial nos quais os mesmos são manuseados pelos trabalhadores de enfermagem, seja durante a assistência ao paciente, na organização da área de trabalho ou na desinfecção e esterilização de materiais durante o processo de trabalho.

\section{REFERÊNCIAS}

1. Felli VEA. Plano de gerenciamento de resíduos químicos hospitalares. Anais eletrônicos. [CD-ROM]. In: Anais do $56^{\circ}$ Congresso Brasileiro de Enfermagem; 2004 Out. 24-29; Gramado, BR [evento na internet] Gramado: ABEn-Seção-RS; 2004. [acesso em 29 mar 2005]. Disponível: http://www.bettina.ufpa.br/ documentos/pgrssatva/bettina.pdf

2. Silva VEF. O desgaste do trabalhador de enfermagem: relação trabalho de enfermagem e saúde do trabalhador. [tese] São Paulo (SP): Escola de Enfermagem da USP; 1996.

3. Costa TF, Felli VEA. Exposição dos trabalhadores de enfermagem às cargas químicas em um hospital público universitário da cidade de São Paulo. Rev. Latino-Am. Enfermagem. 2005;13(4):501-8.

4. Garcia LP, Zanetti-Ramos BG. Gerenciamento dos resíduos de serviços de saúde: uma questão de biossegurança. Cad. Saúde Pública. 2004;20(3):744-52.

5. Xelegati R, Robazzi MLCC. Riscos químicos a que estão submetidos os trabalhadores de enfermagem: uma revisão de literatura. Rev. latino-am enfermagem. 2003;11(3):350-6.

6. Agência Nacional de Vigilância Sanitária - ANVISA. RDC n.306, de 07 de dezembro de 2004. Dispõe sobre o regulamento técnico para o gerenciamento de resíduos de serviços de saúde. Revoga a Resolução ANVISARDC no,33 de 2003. In: Agência Nacional de Vigilância Sanitária (ANVISA, BR). Brasília; 2004. p.1-36.

7. Companhia de Tecnologia de Saneamento Ambiental (CETESB). n. P4.262, de agosto de 2007. Dispõe sobre o gerenciamento de resíduos químicos provenientes de estabelecimentos de serviços de saúde. In: Companhia de Tecnologia de Saneamento Ambiental (CETESB, SP). São Paulo;2007 p. 1-13

8. Centro de Vigilância Sanitária (CVS). N. 21, de 10 de setembro de 2008. Dispõe sobre a norma técnica sobre gerenciamento de resíduos de medicamentos em serviços de saúde. In: Centro de Vigilância Sanitária
CVS: São Paulo; 2008. p. 1-51.

9. Associação Brasileira de Normas Técnicas (ABNT). NBR 10.004. Resíduos sólidos - classificação. Rio de Janeiro; 2004.

10. Brasil. Conselho Nacional do Meio Ambiente (CONAMA). Resolução n.358, de 29 de Abr de 2005. Dispõe sobre o tratamento e destinação final dos resíduos dos serviços de saúde. Revogam-se a Resolução CONAMA n ${ }^{\circ}$ 283, de 2001 e as disposições da Resolução no 5, de 1993, que tratam dos resíduos sólidos oriundos dos serviços de saúde. In: Conselho Nacional de Meio Ambiente (CONAMA, BR). Brasília; 2005. p.1-8.

11. Associação Brasileira de Normas Técnicas (ABNT). NBR 14725-4 Produtos químicos - Informações sobre segurança, saúde e meio ambiente. Parte 4: Ficha de informações de segurança de produtos químicos FISPQ. Rio de Janeiro: 2009.

12. HSDB. Hazardous Substance Data Bank [computer program]. Tomes $\backslash 72001 . H T M$ : Databases within Chembnowledge ${ }^{\mathrm{TM}}$ System plus Ariel GlobalView. Tomes; 2002. [CD-Room]

13. Xelegati R, Robazzi MLCC, Marziale MHL, Haas VJ. Riscos ocupacionais químicos identificados por enfermeiros que trabalham em ambiente hospitalar. Rev. Latino-Am. Enfermagem. 2006;14(2):214-9.

14. Jolibois BGM, Vassal S. Glutaraldehyde in hospital watewater. Arch. Environ. Contam. Toxicol. 2002;42(2);137-144.

15. Mota SM, Magalhães CS, Pordeus IA, Moreira NA; Impacto dos resíduos de serviços de saúde sobre o homem e meio ambiente. Arq. odontol. 2004;40(2):111206.

16. Mallinckrodt Chemicals J.T.Baker. Material Safety Data Sheet - MSDS n.F5522 - Formaldehyde 37\% - MSDS. Canada; 2007.

17. Costa TF, Felli VEA. Acidentes do trabalho com substâncias químicas entre os trabalhadores de enfermagem. Rev Bras Enferm. 2004;57(3):269-73.

18. Silva CE, Hoppe AE. Diagnóstico dos resíduos de serviços de saúde no interior do Rio Grande do Sul. Bio. 2005;10(2):146-51.

19. Costa AMP. Elaboração e avaliação da implantação de um "Modelo Básico" de plano de gerenciamento de 
resíduos de serviços de saúde em unidades hospitalares da Região Metropolitana da Baixada Santista. [dissertação]. São Paulo(SP): Faculdade de Saúde Pública da USP; 2001.

20. Takayanagui AMM. Risco ambiental e o gerenciamento de resíduos nos espaços de um serviço no canadá; um estudo de caso. [tese]. Ribeirão Preto (SP): Escola de Enfermagem de Ribeirão Preto da USP; 2004

21. Salles CLS. Acidentes de trabalho ocorridos com os trabalhadores de saúde nos diferentes processos de um plano de gerenciamento de resíduos de serviço de saúde. Centro de Pós-Graduação, Pesquisa e Extensão, Universidade de Guarulhos; 2008. [acesso em 15 maio 2009]. Disponível: http://tede.ung.br/tde_busca/arquivo.php?codArquivo=77

22. Rodrigues GAS. A enfermagem gerenciando o serviço de lixo hospitalar. Nursing (São Paulo). 2000;28(9):5-7.

23. Sarquis LMM, Felli VEA. Acidentes de trabalho com instrumentos perfuro cortantes entre os trabalhadores de enfermagem. Rev. esc. enfermagem USP. 2002;36(3):222-30.

24. Costa TF. Gerenciamento de resíduos químicos perigosos manuseados pela enfermagem de um hospital universitário. [tese] São Paulo (SP): Escola de Enfermagem da USP; 2009. 